\title{
Trends in erectile dysfunction research from 2008 to 2018: a bibliometric analysis
}

\author{
Jialiang Hui ${ }^{1} \cdot$ Shuhua $\mathrm{He}^{1} \cdot$ Ruiyu Liu ${ }^{1} \cdot$ Qinyu Zeng ${ }^{1} \cdot$ Haibo Zhang $^{1} \cdot$ Anyang Wei $^{1}{ }^{1}$ \\ Received: 13 January 2019 / Revised: 27 February 2019 / Accepted: 16 May 2019 / Published online: 24 June 2019 \\ (c) The Author(s) 2019. This article is published with open access
}

\begin{abstract}
Insufficient penile erection to facilitate vaginal penetration is a medical condition referred to as erectile dysfunction (ED). By the year 2025, the number of ED cases across the world is expected to reach 322 million. There are numerous publications and studies in the field of ED over the past decades. Our aim is to comprehensively analyze the global scientific outputs of ED research and show the trends and hotspots in ED research. Data of publications were downloaded from the Web of Science Core Collection. We used CiteSpace IV and Excel 2016 to analyze literature information, including journals, countries/regions, institutes, authors, citation reports, and research frontiers. Until October 26, 2018, a total of 8880 papers in ED research were identified as published between 2008 and 2018. Journal of Sexual Medicine published the most articles. The United States contributed the most publications and occupied leading positions in H-index value and the number of ESI top papers. Maggi M owned the highest co-citations. The keyword "Oxidative stress" ranked first in the research front-line. The amount of articles published in ED research has been stable from 2008 to 2018. The United States showed enormous progress in ED research, and is still the dominant country. Oxidative stress, vardenafil, and late-onset hypogonadism were the latest research frontiers and should be paid more attention.
\end{abstract}

\section{Introduction}

Insufficient penile erection to facilitate vaginal penetration is a medical condition referred to as erectile dysfunction (ED) $[1,2]$. Its diagnosis dates back to over 5000 years ago based on ancient Egyptian literature [3, 4]. The pervasiveness of erectile dysfunction shows a gradual increase in an age-dependent manner according to a cross-sectional and community-based investigation [5]. Moreover, it was found that the prevalence level of severe and moderate ED was 5 and $17 \%$, respectively, in men of 40-49 age-bracket while in men aged 70-79 years they were 15 and $34 \%$, in that

These authors contributed equally: Jialiang-Hui, Shuhua-He, Ruiyu-Liu

$\triangle$ Haibo Zhang

hai516@163.com

$\triangle$ Anyang Wei

profwei@126.com

1 Department of Urology, Nanfang Hospital, Southern Medical University, 510515 Guangzhou, China order. By the year 2025, the number of ED cases across the world is expected to reach 322 million $[6,7]$.

There are numerous publications and studies in the field of ED over the past decades. But there is no systematic analysis of the publications. To analyze the progress of events in a given area, bibliometric analysis has been developed as it encompasses quantitative measurements utilizing both statistical and geometrical methods $[8,9]$. The bibliometric analyses are primarily directed toward the metrological features of data concerning a specific subject [10], which is often applied in assessing the developments within the field in an extended period. Over the past decades, there have been many bibliometric publications in top medical journals [11-16]. The publishing industry has also broadened its scope beyond researched-based publications to include bibliometric analysis [17].

\section{Materials and methods}

\section{Sources of data and searching strategies}

The articles were retrieved on the same day from the Science Citation Index-Expanded (SCI-E) of the Web of 
Science Core Collection (WoSCC) on October 26, 2018, to prevent biases due to the daily databases updates. MeSH was used to select the following search terms: $=$ "(TS $=$ (Erectile Dysfunction) OR TS $=$ (Dysfunction, Erectile) OR $\mathrm{TS}=$ (Male Sexual Impotence) OR TS $=$ (Impotence, Male Sexual) OR $\mathrm{TS}=($ Sexual Impotence, Male) $\mathrm{OR} \mathrm{TS}=$ (Male Impotence) $\mathrm{OR}$ TS $=$ (Impotence, Male) $\mathrm{OR}$ TS $=$ (Impotence)) AND LANGUAGE:(English) Refined by DOCUMENT TYPES: (Article OR Review) Timespan: 2008-2018. Indexes: SCI-EXPANDED". Review and original research were included in this study.

\section{Data collection}

Two authors working independently downloaded and screened the raw data from WoSCC. The data were analyzed using the CiteSpace IV (Drexel University, Philadelphia, PA, USA) and Excel 2016 (Redmond, WA, USA). In cases where there were discrepancies, they were resolved through discussions.

\section{Data analysis and statistics}

The printing features such as the H-index, impact factor, some annual publications, journal sources, citation counts, journal sources, authors, institutes, and countries/regions, were analyzed using the WoSCC literature analysis wire. The impact factor represents the annual citations received for all the articles published by the journal in a given year [18]. Hence, it provides an estimation of the amount of research data when performing bibliometric analyses. The $\mathrm{H}$-index incorporates the citation impact per publication of institute, country, productivity, etc., and the productivity [19]. This makes it a good tool for measuring the quality of research data.
To study the associations among journals, assess the collaborating teams among countries, institutes, authors, construct visualization maps, capture keywords with strong citation bursts, and identify co-cited authors/references, we used the CiteSpace IV. In this work, 50 most highly cited papers in a one-year slice were used in the individual networks [20-24]. The term frequency-inverse document frequency (TF-IDF) weighting was utilized for the analysis of data in each group. TF-IDF is a statistical algorithm reflecting how necessary a word to a corpus of documents [25].

\section{Results}

\section{Growth forecast and yearly publications}

In total, 8880 articles matched the retrieval criteria. Figure 1 shows the total articles published in each year, with the trend ranging from 866 papers in 2008 to 759 papers in 2017. On average, there were 822 articles per year, and the number of publications per year remained stable. As of October 26, 2018, 662 articles were published in 2018.

\section{Journal distribution}

With regard to publications in the ED subject, there were 1587 academic journals publishing in this subject and Table 1 shows the top 20 journals. Journal of Sexual Medicine (impact factor (IF) $2017=3.339$ ) had the highest publications (1495 articles, 17.724\%), followed by International Journal of Impotence Research (IF $2017=1.517$; 385 publications; 4.564\%), BJU International (IF $2017=$ 4.688; 293 publications; 3.474\%), Urology (IF $2017=$ 2.300; 249 publications; $2.952 \%$ ), and Journal of Urology (IF $2017=5.381 ; 214$ publications; $2.537 \%$ ).

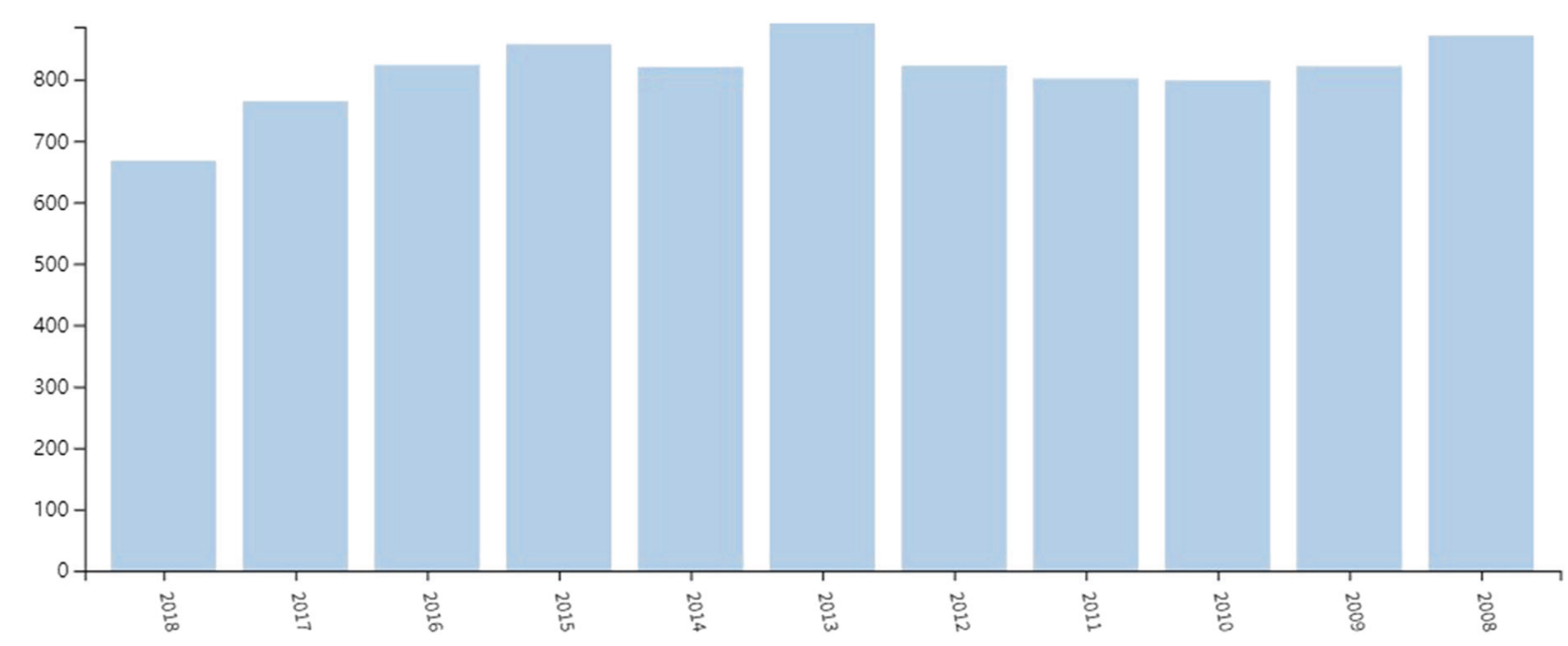

Fig. 1 Publication outputs. The annual number of publication in erectile dysfunction research from 2008 to 2018 
Table 1 The top 20 journals that published articles in erectile dysfunction research

\begin{tabular}{llllll}
\hline Rank & Journal title & Country & Count & Percent & IF 2017 \\
\hline 1 & Journal of Sexual Medicine & USA & 1495 & 17.724 & 3.339 \\
2 & International Journal of Impotence Research & England & 385 & 4.564 & 1.517 \\
3 & BJU International & England & 293 & 3.474 & 4.688 \\
4 & Urology & USA & 249 & 2.952 & 2.300 \\
5 & Journal of Urology & USA & 214 & 2.537 & 5.381 \\
6 & Asian Journal of Andrology & China Mainland & 186 & 2.205 & 3.259 \\
7 & Andrologia & Germany & 169 & 2.004 & 1.588 \\
8 & European Urology & Netherlands & 116 & 1.375 & 17.581 \\
9 & Andrology & USA & 108 & 1.280 & 2.734 \\
10 & Aging Male & England & 106 & 1.257 & 2.500 \\
11 & PLOS One & USA & 95 & 1.126 & 2.766 \\
12 & Journal of Andrology & USA & 79 & 0.937 & $2.473(2014)$ \\
13 & International Journal of Clinical Practice & England & 76 & 0.901 & 2.000 \\
14 & International Urology and Nephrology & Netherlands & 71 & 0.842 & 1.692 \\
15 & Sexual Medicine & England & 67 & 0.794 & 1.457 \\
16 & Urologia Internationalis & Switzerland & 62 & 0.735 & 1.508 \\
17 & International Journal of Urology & Japan & 59 & 0.699 & 1.941 \\
18 & International Braz J Urol & Brazil & 57 & 0.676 & 0.976 \\
19 & World Journal of Urology & USA & 50 & 0.593 & 2.981 \\
20 & Journal of Mens Health & Ireland & 46 & 0.545 & 0.231 \\
\hline & & & & &
\end{tabular}

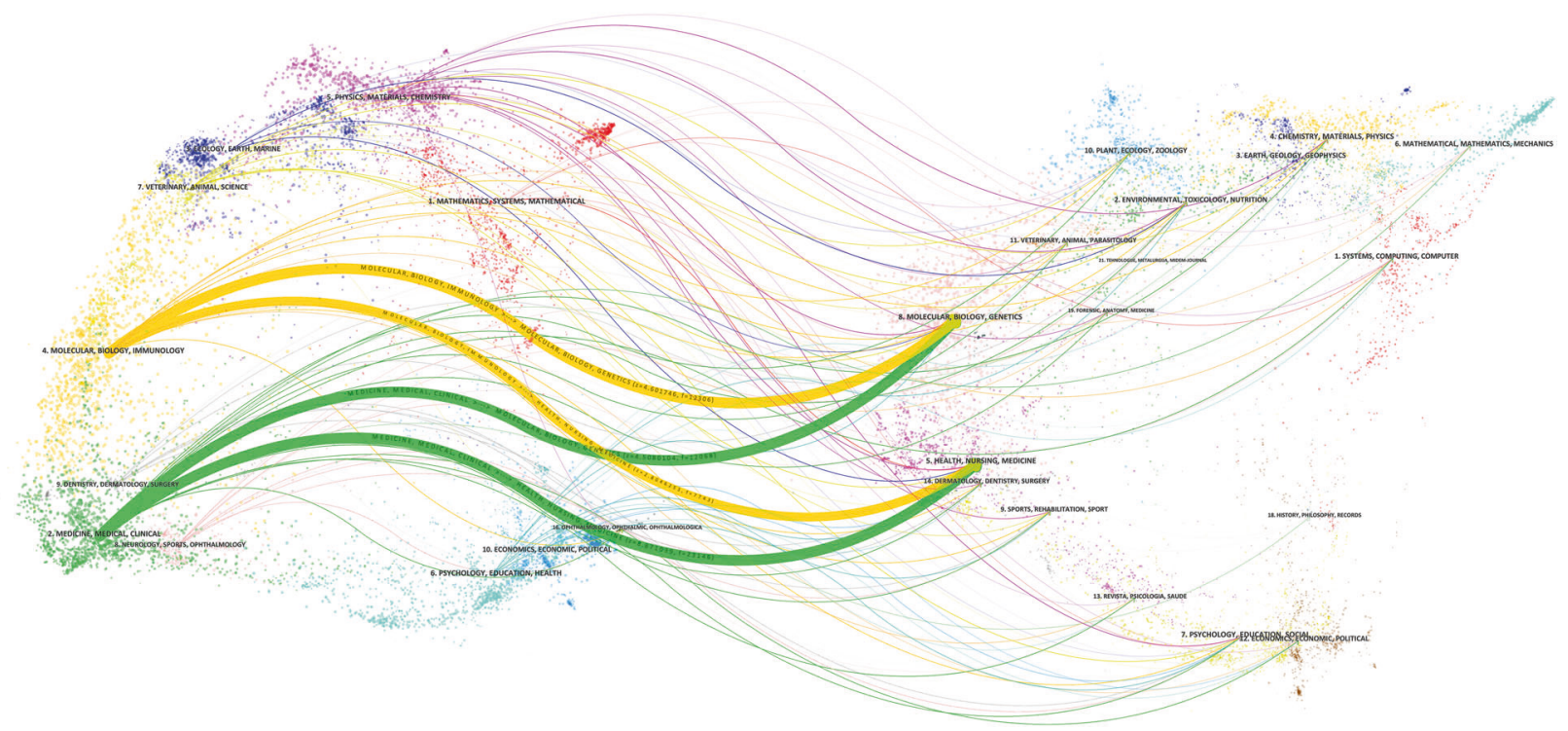

Fig. 2 The dual-map overlay of journals related to erectile dysfunction research. There were four citation paths. The top yellow path, papers published in molecular/biology/immunology journals mostly cited journals in molecular/biology/genetics area; the middle green path, papers published in molecular/biology/immunology journals partially cited journals in health/nursing/medicine area; the middle green path, papers published in medicine/medical/clinical journals partially cited journals in molecular/biology/genetics area; the bottom green path, articles published in medicine/medical/clinical journals partially cited journals in health/nursing/medicine area

Figure 2 displays the dual-map overlay of journals. The right and left side resembled the citing and cited journals maps, individually. The labels showed the description of fields covered by the journal. The lines on the map, originated from the left to the right, served the citation links. There were four main citation paths on the map.

\section{Profiling of institutes and countries}

A total of 114 regions/countries published 8880 articles in ED research. There were very wide collaborating teams among these regions/countries (Fig. 3a). Among the leading 20 regions/countries (Table 2) engaged in ED research, 

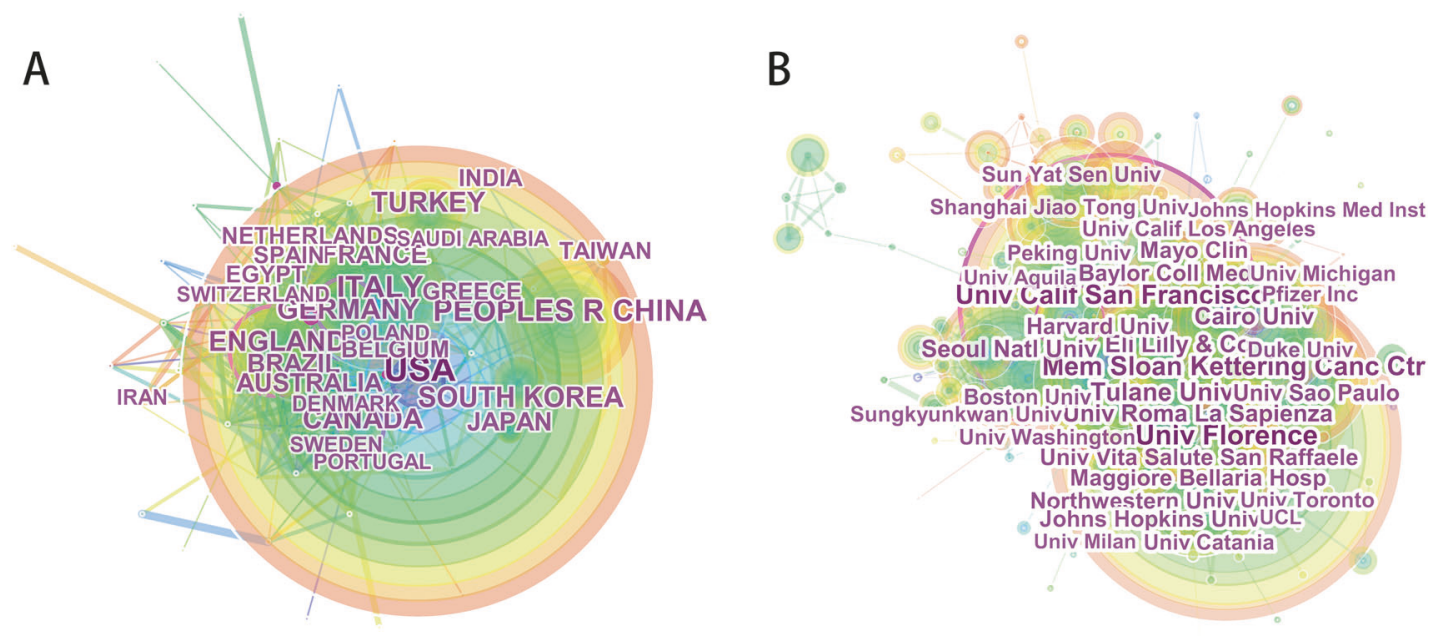

Fig. 3 The distribution of countries and institutes. a The network map of countries/regions that in the case of erectile dysfunction (ED) research. b The network map of institutes involved in erectile dysfunction research

Table 2 The top 20 countries and institutes publications in erectile dysfunction research

\begin{tabular}{|c|c|c|c|c|c|c|}
\hline Rank & Country/region & Count & Percent & Institute & Count & Percent \\
\hline 1 & USA & 2896 & 32.613 & Univ Florence & 218 & 2.455 \\
\hline 2 & Italy & 985 & 11.092 & Univ Calif San Francisco & 185 & 2.083 \\
\hline 3 & Peoples R China & 867 & 9.764 & Mem Sloan Kettering Canc Ctr & 161 & 1.813 \\
\hline 4 & England & 639 & 7.196 & Tulane Univ & 127 & 1.43 \\
\hline 5 & Turkey & 530 & 5.968 & Univ Roma La Sapienza & 112 & 1.261 \\
\hline 6 & Germany & 475 & 5.349 & Cairo Univ & 104 & 1.171 \\
\hline 7 & South Korea & 445 & 5.011 & Eli Lilly Co & 103 & 1.16 \\
\hline 8 & Canada & 427 & 4.809 & Univ Sao Paulo & 97 & 1.092 \\
\hline 9 & Brazil & 405 & 4.561 & Seoul Natl Univ & 96 & 1.081 \\
\hline 10 & Australia & 294 & 3.311 & Univ Vita Salute San Raffaele & 94 & 1.058 \\
\hline 11 & France & 282 & 3.176 & Baylor Coll Med & 92 & 1.036 \\
\hline 12 & Japan & 276 & 3.108 & Maggiore Bellaria Hosp & 92 & 1.036 \\
\hline 13 & Egypt & 244 & 2.748 & Harvard Univ & 89 & 1.002 \\
\hline 14 & Taiwan & 228 & 2.568 & Mayo Clin & 86 & 0.968 \\
\hline 15 & Spain & 221 & 2.489 & Johns Hopkins Univ & 85 & 0.957 \\
\hline 16 & Netherlands & 219 & 2.466 & Northwestern Univ & 84 & 0.946 \\
\hline 17 & Belgium & 172 & 1.937 & Pfizer Inc & 81 & 0.912 \\
\hline 18 & India & 167 & 1.881 & Univ Calif Los Angeles & 77 & 0.867 \\
\hline 19 & Greece & 157 & 1.768 & Univ Washington & 75 & 0.844 \\
\hline 20 & Sweden & 141 & 1.588 & Duke Univ & 73 & 0.822 \\
\hline
\end{tabular}

2896 publications were from the USA, followed by Italy (985), Peoples R China (867), England (639), and Turkey (530).

As shown in the result, about 7449 institutes were engaged in research in the field of ED. Among the institutes, there were extensive collaborations (Fig. 3b). About $36 \%$ of the total publications were from the top 20 institutes (Table 2). Univ Florence topped the list, followed by the
Univ Calif San Francisco, Mem Sloan Kettering Canc Ctr, Tulane Univ, and Univ Roma La Sapienza.

\section{Analysis of highly cited, $\mathrm{H}$-index, and average citations}

Among the top ten rich countries (Fig. 4), the United States contributed the most number of highly cited papers 


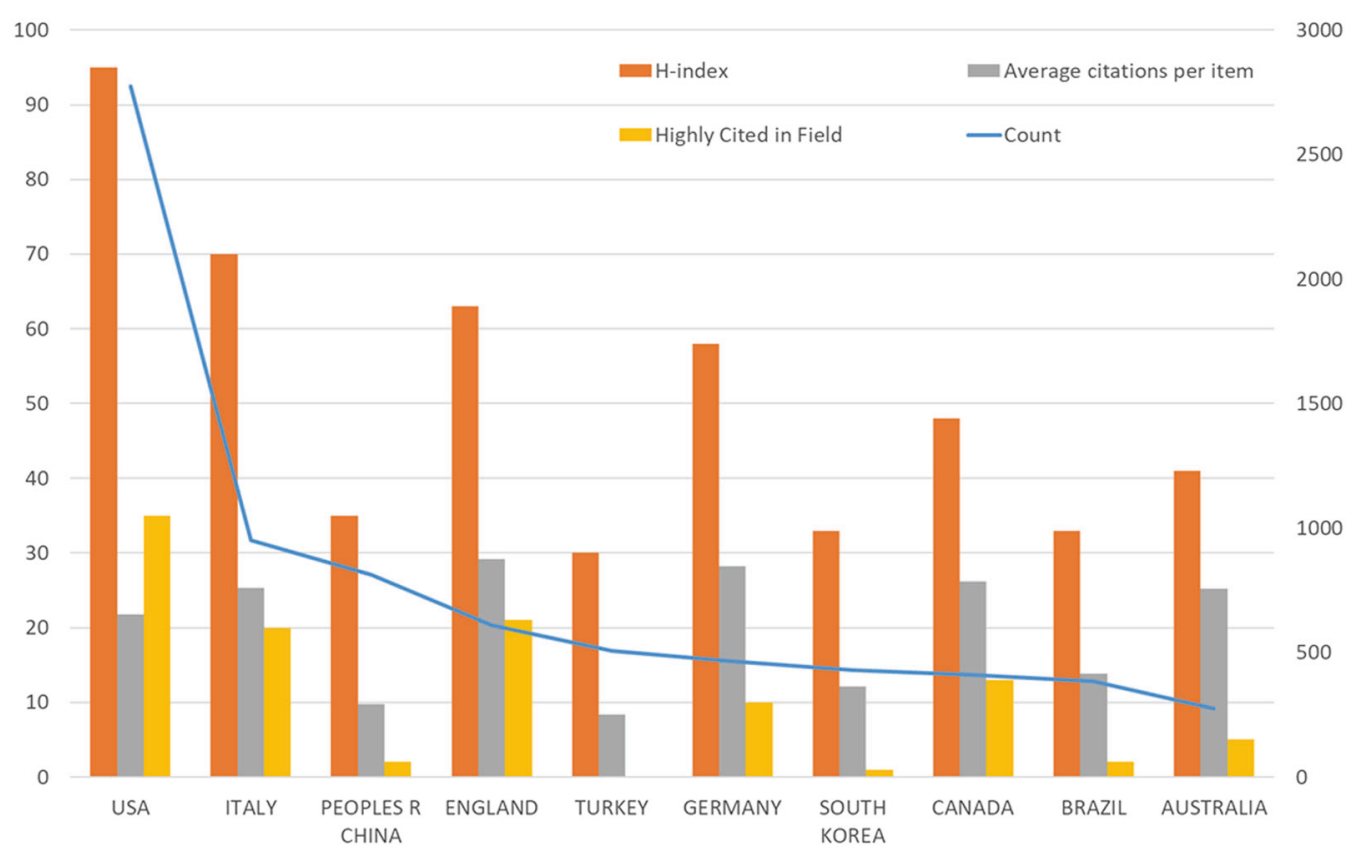

Fig. 4 The distribution of highly cited, H-index, and average citations in the top ten countries

(35) and achieved the highest H-index value (96). Followed by Italy, Peoples R China, England, and Turkey. Out of the figure, France had the highest levels of average citations per item (33.99), but in the overall ranking was the 12th place. Although France is a non-English speaking country, ASSISTANCE PUBLIQUE HOPITAUX PARIS APHP is an important institution in the field of ED research in France. Research support in the field of ED is strong, with more than $40 \%$ of research coming from this institution. Also in France, there are more than 4000 researchers working on ED research, and there are 120 articles by GIULIANA FRANCOIS, accounting for $24.2 \%$.

\section{Profiling of authors}

As shown in the result, 28,321 authors were engaged in ED research. The collaboration network among the authors is shown in Fig. 5a. Of the top 20 contributing authors (Table 3), Maggi M (with 172 articles) was ranked first, followed by Corona G (139 publications), Burnett AL (114 publications), Mulhall JP (104 publications), and Montorsi F (96 publications).

The data of author citations were analyzed using CiteSpace and visualized in a co-citation network (Fig. 5b). For the top 20 co-cited authors (Table 3), Rosen RC (2407 co-citations) was ranked first, followed by Feldman HA (1107 co-citations), Corona G (940 co-citations), Montorsi F (922 co-citations), and Mulhall JP (756 co-citations).

\section{Analysis of references}

To construct a network of co-cited references, the CiteSpace IV was used, and the results are shown in Fig. 6a. As shown in the figure, studies of HATZIMOURATIDIS (2010) [26], THOMPSON (2005) [27], BHASIN (2010) [28], INMAN (2009) [29], and LEWIS (2010) [30] are the most frequently cited documents (all more than 150 times). These may be the focus of the ED field research and the classic literature, which researchers should pay more attention. Furthermore, Fig. $6 \mathrm{c}$ highlights the burst and key literature in the references to present the results (Fig. 6c) better. The terms extracted from the reference list of the articles were used to the name the groups as shown in Fig. 6d. In the network (Fig. 6d), the top4 bulky clusters were named "\#0 radical prostatectomy", "\#1 erectile dysfunction", and "\#2 real-life study", and "\#3 testosterone replacement therapy", respectively. Moreover, Fig. $6 \mathrm{~b}$, d showed the timeline trajectory of the clusters.

\section{Analysis of burst keywords}

The CiteSpace IV tool was used to burst to keywords that showed a high-citation burst (Fig. 7). Exclude keywords that are not research priorities, hose that had citation bursts from 2008 onwards were: "oxidative stress" (2014-2018), "vardenafil" (2008-2013), "late-onset hypogonadism" (2016-2018), "diabetes" (2011-2012), and "sildenafil citrate" (2008-2010) (excluding some keywords that are not directly related to research). 


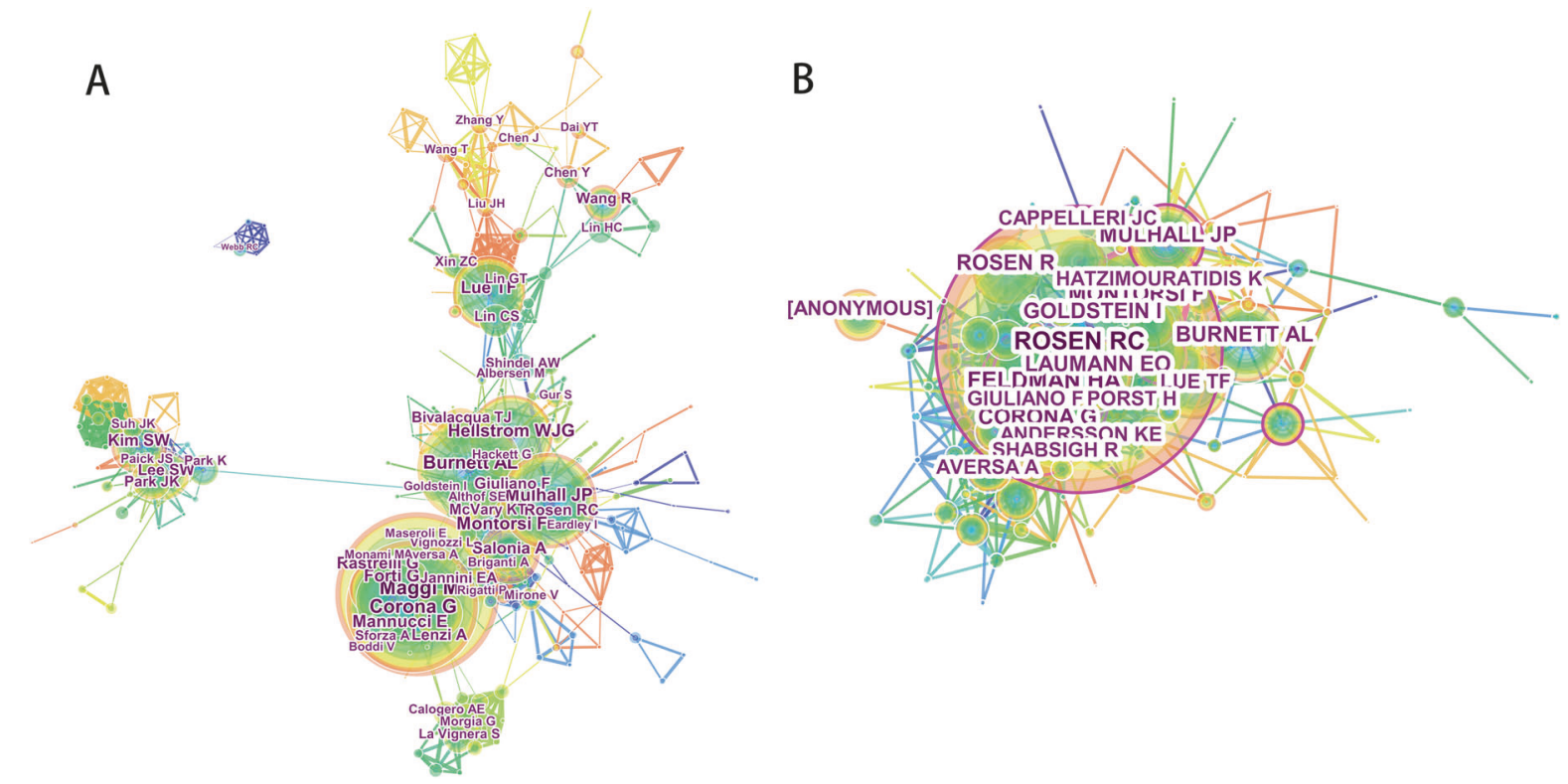

Fig. 5 The distribution of authors. a The network map of active authors offered to erectile dysfunction research. $\mathbf{b}$ The network map of co-cited authors offered to erectile dysfunction research

Table 3 The top 20 authors, co-cited authors, and co-cited references in erectile dysfunction research

\begin{tabular}{|c|c|c|c|c|c|c|}
\hline Rank & Author & Count & Co-cited author & Count & Co-cited reference & Count \\
\hline 1 & Maggi M & 172 & Rosen RC & 2407 & HATZIMOURATIDIS K, 2010, EUR UROL, V57, P804 & 277 \\
\hline 2 & Corona $\mathrm{G}$ & 139 & Feldman HA & 1107 & THOMPSON IM, 2005, JAMA-J AM MED ASSOC, V294, P2996 & 221 \\
\hline 3 & Burnett AL & 114 & Corona $\mathrm{G}$ & 940 & BHASIN S, 2010, J CLIN ENDOCR METAB, V95, P2536 & 172 \\
\hline 4 & Mulhall JP & 104 & Montorsi F & 922 & INMAN BA, 2009, MAYO CLIN PROC, V84, P108 & 161 \\
\hline 5 & Montorsi F & 96 & Mulhall JP & 756 & LEWIS RW, 2010, J SEX MED, V7, P1598 & 158 \\
\hline 6 & Hellstrom WJG & 92 & Burnett AL & 753 & SANDA MG, 2008, NEW ENGL J MED, V358, P1250 & 149 \\
\hline 7 & Mannucci E & 81 & Rosen $\mathrm{R}$ & 727 & WU FCW, 2010, NEW ENGL J MED, V363, P123 & 142 \\
\hline 8 & Lue TF & 80 & Laumann EO & 682 & SHAMLOUL R, 2013, LANCET, V381, P153 & 142 \\
\hline 9 & Forti $\mathrm{G}$ & 79 & Goldstein I & 674 & ROSEN R, 2003, EUR UROL, V44, P637 & 140 \\
\hline 10 & Salonia A & 72 & Lue TF & 657 & SELVIN E, 2007, AM J MED, V120, P151 & 135 \\
\hline 11 & Kim SW & 68 & Porst $\mathrm{H}$ & 570 & MCVARY KT, 2007, J UROLOGY, V177, P1071 & 126 \\
\hline 12 & Rosen RC & 66 & Giuliano F & 567 & MONTORSI F, 2008, EUR UROL, V54, P924 & 121 \\
\hline 13 & Lee SW & 64 & Cappelleri JC & 562 & ESPOSITO K, 2004, JAMA-J AM MED ASSOC, V291, P2978 & 118 \\
\hline 14 & Rastrelli G & 64 & [anonymous] & 546 & GRATZKE C, 2010, J SEX MED, V7, P445 & 107 \\
\hline 15 & Bivalacqua TJ & 59 & Andersson $\mathrm{KE}$ & 545 & MALAVIGE LS, 2009, J SEX MED, V6, P1232 & 103 \\
\hline 16 & lenzi A & 57 & Shabsigh R & 534 & LINDAU ST, 2007, NEW ENGL J MED, V357, P762 & 100 \\
\hline 17 & Giuliano F & 55 & Hatzimouratidis $\mathrm{K}$ & 519 & MCVARY KT, 2007, J UROLOGY, V177, P1401 & 99 \\
\hline 18 & Jannini EA & 52 & Aversa A & 505 & DONG JY, 2011, J AM COLL CARDIOL, V58, P1378 & 98 \\
\hline 19 & Mcvary KT & 52 & Althof SE & 477 & GAZZARUSO C, 2008, J AM COLL CARDIOL, V51, P2040 & 96 \\
\hline 20 & Wang R & 52 & Bivalacqua TJ & 472 & JACKSON G, 2006, J SEX MED, V3, P28 & 95 \\
\hline
\end{tabular}

\section{Discussion}

\section{General information}

The aim of this study was to comprehensively analyze the global scientific outputs of ED research in 2008-2018, and show the trends and hotspots in ED research. Based on the analysis, the publication trend showed a stable trajectory within the search period. To obtain enough number of publications, the time range of publications was set from 2008 at identifying them. We limited the period to the publications made after 2008 to obtain enough number of 

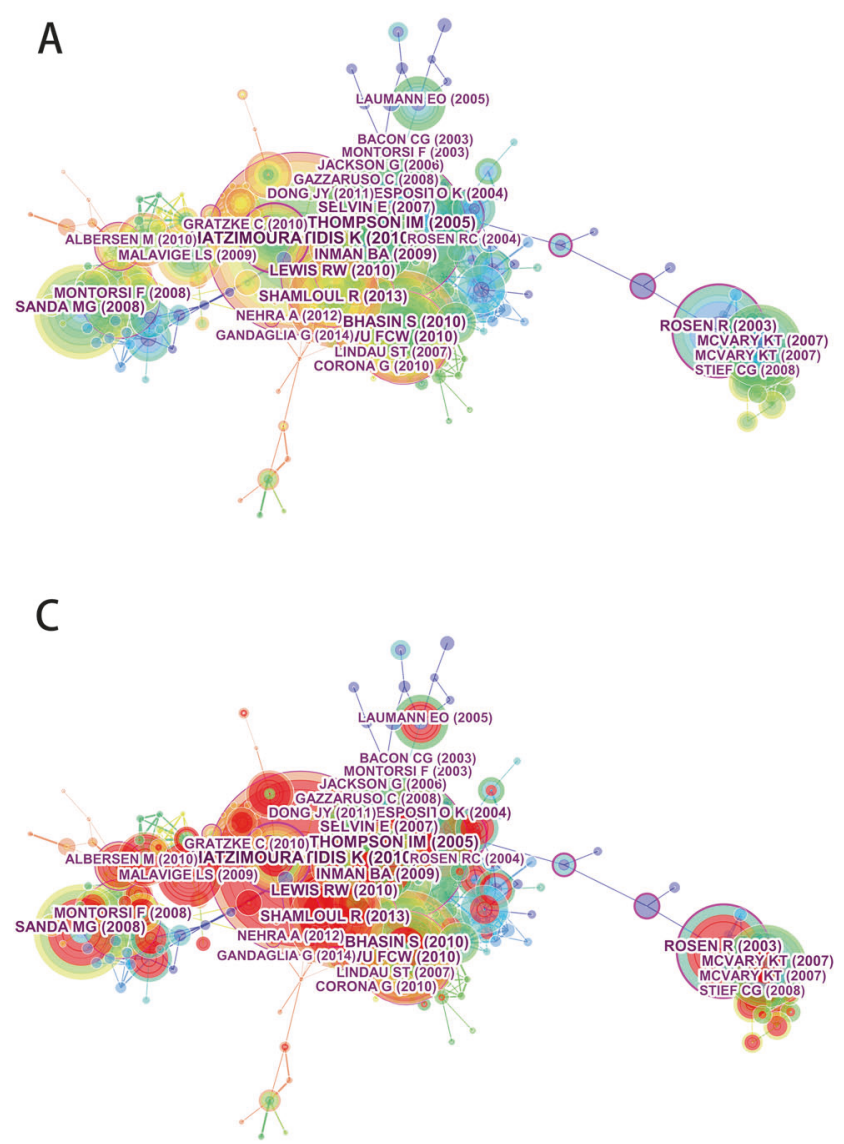

Fig. 6 The analysis of references. a The co-citation map of references from publications in erectile dysfunction (ED) research. $\mathbf{b}$ The timeline view of co-cited references from publications in ED research. $\mathbf{c}$ The
B

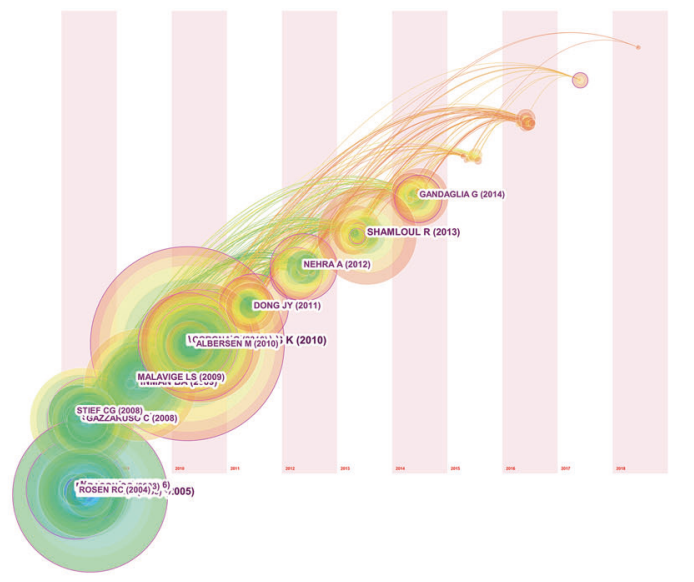

D

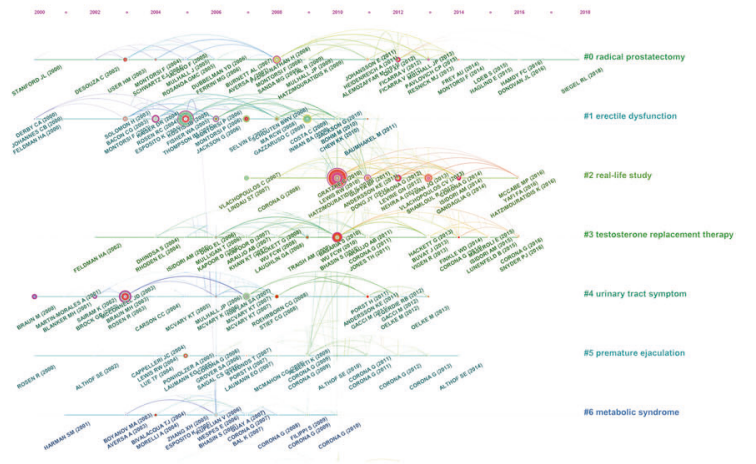

burst words map of references from publications in ED research. $\mathbf{d}$ The timeline view of burst words from publications in ED research publications. With regard to the top 20 academic journals, one journals, European Urology (IF $2017=17.581$ ) had an IF higher than 10; one other, Journal of Urology (IF $2017=5.381$ ) had an IF between 10 and 5; three journals, BJU International (IF $2017=4.688$ ), Journal of Sexual Medicine (IF $2017=3.339$ ), and Asian Journal of Andrology (IF $2017=3.259$ ) had an IF between 5 and 3 .

The number of publications and citations was highest in the USA compared with the top 20 contributing regions/ countries in ED frontier studies. A similar performance was noted about the top $\mathrm{H}$-index and ESI articles as well as the quality of research quality, in which the USA ranked first.

About 3277 papers $(23.994 \%)$ belonged to the top 20 institutes. Similarly, three out of the top five institutes were from the USA and two from Italy.

\section{Citation analysis}

Each author in the top 20 groups had more than 52 publications which were considered to the frontiers in ED research. However, only eight of these authors were listed in the top co-cited authors' list, implying that high-ranking researchers should focus on the quality of research in addition to the number of papers.

As shown in Fig. 6b, analysis of the timeline view of the co-citation clusters showed that the highly co-cited articles were obtained within 2008-2014. Twenty-nine items were identified between 2008 and 2014 from the top 50 co-cited articles retrieved using CiteSpace IV. Hence, this timeframe can be regarded as "golden period" in the ED research in the last decade. The top 20 co-cited articles are shown in Table 3. A paper published by Hatzimouratidis $\mathrm{K}$ in 2010 received the highest number of citations, seconded by 221 co-citations for a paper by Thompson IM in 2005, Bhasin S (2010, 172 co-citations), Inman BA (2009, 161 co-citations), and Lewis RW (2010, 158 co-citations), who published papers in Jama-J Am Med Assoc, J Clin Endocr Metab, Mayo Clin Proc, and J Sex Med. Additional highimpact factor has generated more articles on ED research in the last decade, e.g., Lancet (five articles) and the New England Journal of Medicine (four articles). These journals contributed significantly to the ED field. 


\section{Top 20 Keywords with the Strongest Citation Bursts}

\begin{tabular}{lrrrr}
\multicolumn{1}{c}{ Keywords } & \multicolumn{1}{c}{ Year } & Strength & Begin & End \\
metaanalysis & 2008 & $\mathbf{5 1 . 0 0 7 8}$ & 2014 & 2018 \\
impact & 2008 & $\mathbf{3 4 . 0 1 4}$ & 2016 & 2018 \\
oxidative stress & 2008 & 31.4832 & 2014 & 2018 \\
epidemiology & 2008 & $\mathbf{3 0 . 1 7 6}$ & 2008 & 2012 \\
safety & 2008 & 28.6506 & 2014 & 2016 \\
vardenafil & 2008 & 27.2579 & 2008 & 2013 \\
questionnaire & 2008 & 23.8359 & 2008 & 2009 \\
late onset hypogonadism & 2008 & 20.7615 & 2016 & 2018 \\
diabete & 2008 & 19.897 & 2011 & 2012 \\
depression & 2008 & 16.5566 & 2012 & 2014 \\
satisfaction & 2008 & 15.7983 & 2014 & 2015 \\
experience & 2008 & 15.6891 & 2016 & 2018 \\
sildenafil citrate & 2008 & 15.5314 & 2008 & 2010 \\
diabetes mellitus & 2008 & 15.1722 & 2012 & 2013 \\
risk & 2008 & 14.4139 & 2015 & 2018 \\
placebo controlled trial & 2008 & 13.0432 & 2013 & 2014 \\
peni & 2008 & $\mathbf{6 . 4 5 3 3}$ & 2012 & 2013 \\
premature ejaculation & 2008 & $\mathbf{6 . 0 7 7 6}$ & 2014 & 2015 \\
united states & 2008 & $\mathbf{3 . 1 0 3}$ & 2015 & 2016 \\
hypogonadism & 2008 & $\mathbf{2 . 6 7 8 3}$ & 2009 & 2010 \\
\hline
\end{tabular}

Fig. 7 The keywords with strong citation bursts in articles related to erectile dysfunction research published from 2008 to 2018

\section{Research frontiers}

The burst keywords were identified using the CiteSpace IV, which may be used to predict research hinterlands. In Fig. 7, the red lines represented the period of citation bursts, while blue lines represent the time interval. The following list contains the three frontiers of ED research:

\section{Oxidative stress}

Compared with the general population, the occurrence of ED in men with diabetes is about threefold higher [31, 32]. Many factors are associated with the occurrence of ED, including neurological insults and vascular as well as other metabolic disorders [33]. Chronically atmospheric glucose collections were found to increase the production of nitrogen species (RNS) and reactive oxygen (ROS), which in turn causes glycation end-products (AGE) [34]. Following phenomenon, alterations in the levels of endothelial or neuronal-derived nitric oxide (NO) may compromise the vasorelaxation mechanisms in the diabetic corpus cavernosum $[35,36]$. Decreased levels of NO is thought to cause a low response of diabetic men with ED to oral phosphodiesterase-5 inhibitor therapies [37]. Apart from the alterations to penile vasorelaxation, elevated ROS decreases the levels of antioxidants and lipid peroxidation which leads to damages the DNA and eventually the cavernosal cells structures and functions [38, 39]. Several studies had provided evidence that ROS exerted detrimental effects on ED. The observations have demonstrated that the application of antioxidants increases endothelial NO synthase (eNOS) and reduces superoxide formation $(\mathrm{O} 2-)$ thereby improving diabetic ED [38, 40-42].

\section{II. vardenafil: phosphodiesterase-5}

Phosphodiesterase-5 (PDE-5) is a cyclic guanosine monophosphate (cGMP)-specific phosphodiesterase (PDE) that is highly expressed in the penile corpus cavernosum, and PDE-5 inhibitors, such as Vardenafil, are used to treat ED. Vardenafil highly specific and potent PDE-5 inhibitor which is used to treat ED. Its mechanism of action involves smooth muscle relaxation, which is a critical factor for penile erection [43]. Vardenafil is 5-10 fold potent compared with sildenafil, another typical PDE-5 inhibitor [44]. It is well-tolerated, and has an excellent safety profile and few adverse effects. However, some side-effects such as nasal congestion, indigestion, flushing, and headache are associated with its use [45, 46]. Vardenafil has a rapid mode of action, and therefore ED patients achieve sufficient erection within $10-15 \mathrm{~min}$ following drug intake [47, 48]. During its hepatic metabolism, 14 metabolites are formed, of which $\mathrm{N}$-desethyl vardenafil (M1) is the most predominant, and it has been found to be pharmacologically active $[49,50]$.

\section{Late-onset hypogonadism}

Serum testosterone levels decrease in men with aging at the rate of $1-2 \%$ per year after the age of 40 . The clinical condition of testosterone decreased with specific symptoms has been widely accepted as late-onset hypogonadism (LOH) syndrome [51]. The Massachusetts Male Aging Study demonstrated that prevalence of $\mathrm{LOH}$ syndrome in men between the ages of 40 and 69 ranged from 6.0 to $12.3 \%$ and 2.4 million men in the United States were estimated to be affected [52]. Widely recognized clinical signs of LOH syndrome include ED, decreases in muscle mass and strength, anemia, obesity, osteoporosis, depression, and deterioration of insulin resistance [53-55]. Therefore, LOH syndrome is a clinical condition that could affect the function of multiple organ systems, and LOH syndrome itself is an essential sign of many other potentially dangerous states. Testosterone replacement therapy (TRT) is a widely accepted treatment in the prevention and amelioration of many of the symptoms and conditions associated with $\mathrm{LOH}$ syndrome [55]. 


\section{Strengths and limitations}

To the immeasurable of our knowledge, this study is the first bibliometric analysis on ED research bearing over the past decade. The data analysis manner was relatively physical. Nevertheless, most publications retrieved from the database were written in English, causing incomplete analysis to some extent. Furthermore, this study consisted particularly of original and reviewed articles published between 2008 and 2018 and classified by the Web of Science. It may not be enough to describe all ED literature, such as other record types published in journals, books, and conferences were not included. The analysis in this study was based on articles recorded in the SCI-E of the WoSCC. Each journal to which the SCI-E articles belong had its corresponding citation report provided by the Web of Science. Although other databases such as PubMed, Scopus, and Embase could give a broader range of coverage, much of the "extra coverage" could be credited to journals with potentially limited readers.

Given that our objective was to conduct a high-quality bibliometric analysis to identify research trends in the core of the ED field, the SCI-E articles from WoSCC may be the only suitable choice. Accordingly, the results from other databases were not included. Finally, although the Web of Science database is still updating, this study covers the vast majority of papers in ED research since 2008; new data may not influence the final results.

In conclusion, the number of publications in ED research has been increasing over the past decade. The United States, Italy, and China were the top three countries contributing to ED studies. There were active collaborations between developed countries. The United States was still the autocratic country engaged in ED research.

Rosen RC, Feldman HA, and Corona G may be ideal candidates for academic cooperation. Oxidative stress, vardenafil, late-onset hypogonadism, diabetes, and sildenafil citrate may be hinterlands in this field, and researchers should pay close consideration to relevant studies in the coming years.

Acknowledgements This study was supported by grant (No. 81571433) from the The National Natural Science Foundation of China and (No. 2017A030313453) from the Science and Technology Projects of Guangdong Province.

Author contributions $\mathrm{SH}$ and $\mathrm{JH}$ conceived and designed the analysis, download and analyzed the data, contributed analysis tools, prepared figures and/or tables, authored or reviewed drafts of the paper, approved the final draft. RL and QZ download and analyzed the data, authored or reviewed drafts of the paper, approved the final draft. HZ and $\mathrm{AW}$ conceived and designed the analysis, prepared figures and/or tables, authored or reviewed drafts of the paper, approved the final draft.

\section{Compliance with ethical standards}

Conflict of interest The authors declare that they have no conflict of interest.

Publisher's note: Springer Nature remains neutral with regard to jurisdictional claims in published maps and institutional affiliations.

Open Access This article is licensed under a Creative Commons Attribution 4.0 International License, which permits use, sharing, adaptation, distribution and reproduction in any medium or format, as long as you give appropriate credit to the original author(s) and the source, provide a link to the Creative Commons license, and indicate if changes were made. The images or other third party material in this article are included in the article's Creative Commons license, unless indicated otherwise in a credit line to the material. If material is not included in the article's Creative Commons license and your intended use is not permitted by statutory regulation or exceeds the permitted use, you will need to obtain permission directly from the copyright holder. To view a copy of this license, visit http://creativecommons. org/licenses/by/4.0/.

\section{References}

1. Consensus development conference statement. National Institutes of Health. Impotence. December 7-9, 1992. Int J Impot Res. 1993;5:181-284.

2. NIH Consensus Conference. Impotence. NIH consensus development panel on impotence. Jama. 1993;270:83-90.

3. Shamloul R, Ghanem H. Erectile dysfunction. Lancet. 2013;381: 153-65.

4. Shah J. Erectile dysfunction through the ages. BJU Int. 2002; 90:433-41.

5. Feldman HA, Goldstein I, Hatzichristou DG, Krane RJ, McKinlay JB. Impotence and its medical and psychosocial correlates: results of the Massachusetts Male Aging Study. J Urol. 1994;151:54-61.

6. Bacon CG, Mittleman MA, Kawachi I, Giovannucci E, Glasser DB, Rimm EB. Sexual function in men older than 50 years of age: results from the health professionals follow-up study. Ann Intern Med. 2003;139:161-8.

7. Ayta IA, McKinlay JB, Krane RJ. The likely worldwide increase in erectile dysfunction between 1995 and 2025 and some possible policy consequences. BJU Int. 1999;84:50-56.

8. Pritchard A. Statistical bibliography or bibliometrics? J Doc. 1969;25:348-9.

9. Dalpé R. Bibliometric analysis of biotechnology. Scientometrics. 2002;55:189-213.

10. Ellegaard O, Wallin JA. The bibliometric analysis of scholarly production: how great is the impact? Scientometrics. 2015; 105:1809-31.

11. Aggarwal A, Lewison G, Idir S, Peters M, Aldige C, Boerckel $\mathrm{W}$, et al. The state of lung cancer research: a global analysis. J Thorac Oncol: Off Publ Int Assoc Study Lung Cancer. 2016;11:1040-50.

12. Almeida-Guerrero A, Olaya-Gomez JC, Sanchez-Ramirez N, Murillo-Garcia DR, Cardona-Ospina JA, Lagos-Grisales GJ, et al. Mitigation of the global impact of Lassa fever: have we investigated enough about this arenavirus? - a bibliometric analysis of Lassa Fever research. Travel Med Infect Dis. 2018;24:13-14.

13. Azer SA. The top-cited articles in medical education: a bibliometric analysis. Acad Med: J Assoc Am Med Coll. 2015;90:1147-61. 
14. Baek S, Yoon DY, Lim KJ, Cho YK, Seo YL, Yun EJ. The most downloaded and most cited articles in radiology journals: a comparative bibliometric analysis. Eur Radiol. 2018;28: 4832-4838.

15. Bruggmann D, Pulch K, Klingelhofer D, Pearce CL, Groneberg DA. Ovarian cancer: density equalizing mapping of the global research architecture. Int J health Geogr. 2017;16:3.

16. Khan NR, Saad H, Oravec CS, Norrdahl SP, Fraser B, Wallace D, et al. An analysis of publication productivity during residency for 1506 neurosurgical residents and 117 residency departments in North America. Neurosurgery. 2018;84:857-67.

17. Wakeling S, Willett P, Creaser C, Fry J, Pinfield S, Spezi V. Transitioning from a conventional to a 'Mega' Journal: a bibliometric study of the journal medicine. Publications. 2017;5:7.

18. Garfield E. The history and meaning of the journal impact factor. Jama. 2006;295:90-93.

19. Costas R, Bordons M. The h-index: advantages, limitations and its relation with other bibliometric indicators at the micro level. J Informetr. 2007;1:193-203.

20. Chen C. Searching for intellectual turning points: progressive knowledge domain visualization. Proc Natl Acad Sci USA. 2004;101(Suppl 1):5303-10.

21. Chen CM. CiteSpace II: detecting and visualizing emerging trends and transient patterns in scientific literature. J Am Soc Inf Sci Technol. 2006;57:359-77.

22. Chen C, Ibekwe-Sanjuan F, Hou J. The structure and dynamics of cocitation clusters: a multiple-perspective cocitation analysis. J Am Soc Inf Sci Technol. 2010;61:1386-409.

23. Chen C. Predictive effects of structural variation on citation counts. J Am Soc Inf Sci Tec. 2012;63:431-49.

24. Chen C, Leydesdorff L. Patterns of connections and movements in dual-map overlays: a new method of publication portfolio analysis. J Assoc Inf Sci Technol. 2014;65:334-51.

25. Ramos J. Using tf-idf to determine word relevance in document queries. In: Proceedings of the First Instructional Conference on Machine Learning 2003. http://citeseerx.ist.psu.edu/viewdoc/dow nload?doi $=10 \cdot 1 \cdot 1 \cdot 121.1424 \&$ rep $=$ rep $1 \&$ type $=$ pdf.

26. Hatzimouratidis K, Amar E, Eardley I, Giuliano F, Hatzichristou D, Montorsi F, et al. Guidelines on male sexual dysfunction: erectile dysfunction and premature ejaculation. Eur Urol. 2010; 57:804-14.

27. Thompson IM, Tangen CM, Goodman PJ, Probstfield JL, Moinpour CM, Coltman CA. Erectile dysfunction and subsequent cardiovascular disease. Jama. 2005;294:2996-3002.

28. Bhasin S, Cunningham GR, Hayes FJ, Matsumoto AM, Snyder PJ, Swerdloff RS, et al. Testosterone therapy in men with androgen deficiency syndromes: an endocrine society clinical practice guideline. J Clin Endocrinol Metab. 2010; 95:2536-59.

29. Inman BA, Sauver JL, Jacobson DJ, McGree ME, Nehra A, Lieber MM, et al. A population-based, longitudinal study of erectile dysfunction and future coronary artery disease. Mayo Clin Proc. 2009;84:108-13.

30. Lewis RW, Fugl-Meyer KS, Corona G, Hayes RD, Laumann EO, Moreira ED Jr., et al. Definitions/epidemiology/ risk factors for sexual dysfunction. J Sex Med. 2010;7(4 Pt 2):1598-607.

31. Matsui H, Sopko NA, Hannan JL, Bivalacqua TJ. Pathophysiology of erectile dysfunction. Curr drug targets. 2015;16:411-9.

32. Rosen RC, Fisher WA, Eardley I, Niederberger C, Nadel A, Sand $\mathrm{M}$, et al. The multinational men's attitudes to life events and sexuality (MALES) study: I. prevalence of erectile dysfunction and related health concerns in the general population. Curr Med Res Opin. 2004;20:607-17.

33. Brownlee M. Biochemistry and molecular cell biology of diabetic complications. Nature. 2001;414:813-20.
34. Newsholme P, Haber EP, Hirabara SM, Rebelato EL, Procopio J, Morgan D, et al. Diabetes associated cell stress and dysfunction: role of mitochondrial and non-mitochondrial ROS production and activity. J Physiol. 2007;583(Pt 1):9-24.

35. Agarwal A, Nandipati KC, Sharma RK, Zippe CD, Raina R. Role of oxidative stress in the pathophysiological mechanism of erectile dysfunction. J Androl. 2006;27:335-47.

36. Bivalacqua TJ, Usta MF, Kendirci M, Pradhan L, Alvarez X, Champion HC, et al. Superoxide anion production in the rat penis impairs erectile function in diabetes: influence of in vivo extracellular superoxide dismutase gene therapy. J Sex Med. 2005;2:187-97. discussion 197-188.

37. Saenz de Tejada I, Anglin G, Knight JR, Emmick JT. Effects of tadalafil on erectile dysfunction in men with diabetes. Diabetes Care. 2002;25:2159-64.

38. Tuncayengin A, Biri H, Onaran M, Sen I, Tuncayengin O, Polat F, et al. Cavernosal tissue nitrite, nitrate, malondialdehyde and glutathione levels in diabetic and non-diabetic erectile dysfunction. Int J Androl. 2003;26:250-4.

39. Zhang Q, Radisavljevic ZM, Siroky MB, Azadzoi KM. Dietary antioxidants improve arteriogenic erectile dysfunction. Int $\mathrm{J}$ Androl. 2011;34:225-35.

40. Bivalacqua TJ, Musicki B, Usta MF, Champion HC, Kadowitz PJ, Burnett AL, et al. Endothelial nitric oxide synthase gene therapy for erectile dysfunction. Curr Pharm Des. 2005;11:4059-67.

41. Yu W, Wan Z, Qiu XF, Chen Y, Dai YT. Resveratrol, an activator of SIRT1, restores erectile function in streptozotocin-induced diabetic rats. Asian J Androl. 2013;15:646-51.

42. Zhang XR, Zhang ZJ, Zhu RX, Yuan YG, Jenkins TA, Reynolds GP. Sexual dysfunction in male schizophrenia: influence of antipsychotic drugs, prolactin and polymorphisms of the dopamine D2 receptor genes. Pharmacogenomics. 2011;12:1127-36.

43. Keating GM, Scott LJ. Vardenafil: a review of its use in erectile dysfunction. Drugs. 2003;63:2673-703.

44. Saenz de Tejada I, Angulo J, Cuevas P, Fernandez A, Moncada I, Allona A, et al. The phosphodiesterase inhibitory selectivity and the in vitro and in vivo potency of the new PDE5 inhibitor vardenafil. Int J Impot Res. 2001;13:282-90.

45. Chung E, Brock GB. A state of art review on vardenafil in men with erectile dysfunction and associated underlying diseases. Expert Opin Pharmacother. 2011;12:1341-8.

46. Young JM. Vardenafil. Expert Opin Investig drugs. 2002;11: 1487-96.

47. Francesco Montorsi MD, Harin Padma-Nathan MD, Jacques Buvat MD, Hartwig Schwaibold MD, Beneke M, Ernst Ulbrich $\mathrm{MD}$, et al. Earliest time to onset of action leading to successful intercourse with vardenafil determined in an at-home setting: a randomized, double-blind, placebo-controlled trial. J Sex Med. 2004;1:168-78.

48. Valiquette L, Montorsi F, Hellstrom WJ, Giuliano F, Homering $\mathrm{M}$, Taylor T, et al. Penetration and maintenance of erection with vardenafil: a time-from-dosing analysis. Can J Urol. 2005;12:2687-98. discussion 2699.

49. Gresser U, Gleiter $\mathrm{CH}$. Erectile dysfunction: comparison of efficacy and side effects of the PDE-5 inhibitors sildenafil, vardenafil and tadalafil-review of the literature. Eur J Med Res. 2002;7:435-46.

50. Ormrod D, Easthope SE, Figgitt DP. Vardenafil. Drugs Aging. 2002;19:217-27.

51. Harman SM, Metter EJ, Tobin JD, Pearson J, Blackman MR. Baltimore Longitudinal Study of Aging. Longitudinal effects of aging on serum total and free testosterone levels in healthy men. J Clin Endocrinol Metab. 2001;86:724-31.

52. Araujo AB, O'Donnell AB, Brambilla DJ, Simpson WB, Longcope C, Matsumoto AM, et al. Prevalence and incidence of androgen deficiency in middle-aged and older men: estimates 
from the Massachusetts Male Aging Study. J Clin Endocrinol Metab. 2004;89:5920-6.

53. Bassil N, Alkaade S, Morley JE. The benefits and risks of testosterone replacement therapy: a review. Ther Clin risk Manag. 2009;5:427-48.

54. Lunenfeld B, Mskhalaya G, Zitzmann M, Arver S, Kalinchenko S, Tishova $\mathrm{Y}$, et al. Recommendations on the diagnosis, treatment and monitoring of hypogonadism in men. Aging Male. 2015; 18:5-15.

55. Wang C, Nieschlag E, Swerdloff R, Behre H, Hellstrom W, Gooren L, et al. ISA, ISSAM, EAU, EAA and ASA recommendations: investigation, treatment and monitoring of late-onset hypogonadism in males. Aging Male. 2009; $12: 5-12$. 